\section{hommes}

\section{Hommes \& migrations}

Revue française de référence sur les dynamiques

migratoires

$1324 \mid 2019$

Religion et discrimination

\title{
Adrien Bosc, Capitaine
}

Paris, Stock, 2018, 400 p., $22 €$

\section{Nihad Jnaid}

\section{OpenEdition \\ 1 Journals}

\section{Édition électronique}

URL : https://journals.openedition.org/hommesmigrations/8896

DOI : 10.4000/hommesmigrations.8896

ISSN : 2262-3353

\section{Éditeur}

Musée national de l'histoire de l'immigration

\section{Édition imprimée}

Date de publication : 1 janvier 2019

Pagination : 171-172

ISBN : 978-2-919040-44-5

ISSN : $1142-852 X$

\section{Référence électronique}

Nihad Jnaid, « Adrien Bosc, Capitaine », Hommes \& migrations [En ligne], 1324 | 2019, mis en ligne le 01 janvier 2019, consulté le 08 janvier 2022. URL : http://journals.openedition.org/hommesmigrations/ 8896 ; DOI : https://doi.org/10.4000/hommesmigrations.8896 


\section{Adrien Bosc \\ Capitaine}

Paris, Stock, 2018, 400 pages, 22 euros.
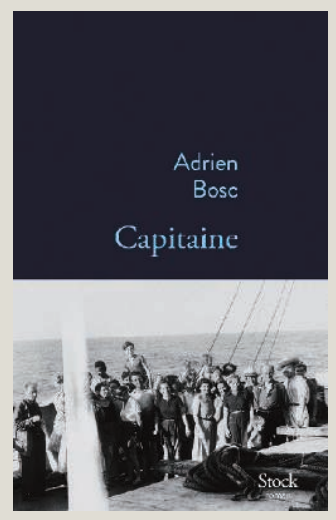

À partir d'une photographie, Adrien Bosc s'empare de l'histoire d'un bateau, Capitaine-Paul-Lemerle, qui quitte Marseille le 24 mars 1941 en direction des Antilles. À son bord s'agrège "une concentration d'une société perdue»: des exilés fuyant la France de Vichy, des Espagnols qui ont perdu la guerre, des Juifs chassés d'Europe, des relégués, des artistes, des écrivains, et des anonymes.

Un groupe de deux cent cinquante personnes mues par un destin commun décide de partir vers les Amériques: «Nous disons que l'Atlantique est pour notre civilisation ce qu'était la Méditerranée pour le monde antique, une mer intérieure.» Sur ce bateau inhospitalier «PÔVRE MERLE», les passagers s'occupent à discuter, rêver, écrire, à essuyer des tempêtes et à trouver le temps long. "Il y avait pour les émigrants prisonniers du bateau, condamnés à se côtoyer, une délectation à relater le péril, le dramatiser, l'ennoblir, romancer son sauvetage, partager ce sentiment d'avoir échappé au pire, d'être déjà des survivants, des rescapés d'un naufrage plus vaste. On se savait d'ailleurs en sursis, prêt à être débarqué n'importe où, arraisonné, torpillé, détourné, ramené à la case départ.»

L'auteur mène l'enquête, fouille, compile, invente et assemble les pièces de ce puzzle pour raconter le périple de personnes réunies par leur soif de la liberté: «Toutes les phrases en italique sont extraites de textes, écrits, journaux, relations de ce périple par les voyageurs. Toutes les 
références sont indiquées en fin d'ouvrage. » Le lecteur est averti et le ton est donné, comme pour éveiller sa curiosité. Une citation de Walter Benjamin vient compléter cet arsenal introductif: «Articuler historiquement le passé ne signifie pas le connaître "tel qu'il a été effectivement", mais bien plutôt devenir maître d'un souvenir tel qu'il brille à l'instant d'un péril.»

Le récit historique est non seulement relaté, mais documenté et interprété. Adrien Bosc tisse un roman à la fois historique et fictionnel, alterne les faits et les enquêtes de terrain car "une quête ne saurait être accomplie sans offrir dans son épilogue la résolution d'un mystère». Et quoi de plus logique pour résoudre l'énigme du portrait de Berthe Morisot que de se rendre au musée d'Orsay: "Je m'étais rendu au musée d'Orsay, j'avais questionné les conservateurs sur l'acquisition à New York d'une toile de Degas ou de Manet, un petit portrait, ou l'apparition même des années plus tard d'un tableau disparu. Je fis chou blanc. Adieu Berthe.»

À la description de la traversée collective succèdent les démarches qu'entreprend l'auteur pour élucider tel détail d'une correspondance ou telle note illustrant un échange. En témoignent les merveilleux extraits du journal de Victor Serge: «De quel énorme brasier approchons-nous? L'espace s'emplit de chaleur, mer uniformément grise, temps couvert. Calme dissolvant, puis légère excitation nerveuse. "L'ambiance

équatoriale", dit Lévi-Strauss.»

"Dès 5 heures 30 le soleil martyrisait le pont, une chaleur écrasante, pesante, brûlant la bâche jusqu'à changer l'abri en étude - ainsi, à peine couverts d'un trait de lumière, les passagers s'éveillaient et arpentaient le pont comme des revenants, hagards, l'œil perdu au loin, à la recherche de l'île. On vit rassemblé à l'avant du cargo un trio qu'on rêva plaisanter entre chien et loup - André Breton, Claude Lévi-Strauss, Victor Serge.»

Nous sommes le 27 avril 1941, l'heure de la Libération n'a pas encore sonné en France, mais à Fort-de-France, André Breton découvre la poésie d'Aimé Césaire qui propose dans la revue Tropiques de lutter contre le «Paupérisme intellectuel et contre le Mépris des couleurs de la vie». La rencontre a lieu le lendemain - «autour de la table, on trouvait René Ménil, Aimé et Suzanne Césaire, Breton et Jacqueline».
Adrien Bosc voyage avec ses personnages et les accompagne dans leur mouvement vers d'autres terres. II tisse une odyssée exceptionnelle et saisit des moments qui mêlent littérature, destins individuels et destin collectif. Nul besoin d'inventer des personnages, il suffit de plonger dans les lettres échangées et de suivre les liens entre, d'une part, les passagers du bateau, Claude Lévi-Strauss, André, Jacqueline et Aube Breton, Anna Seghers et Victor Serge, Germaine Krull, Jacques Rémy, Alfred Kantorowicz et Wifredo Lam et, d'autre part, leurs amis, Skira, Camus, Michel Leiris, Francis et Tanguy entre autres.

Ce huis clos éprouvant n'est pas moins protecteur comme Claude Lévi-Strauss l'écrit à ses parents: "De ce qui se passe dans le Monde, je ne sais à peu près rien depuis un mois, et le peu que je sais m'enlève toute envie d'en connaître davantage.»

Quitter son pays, le fuir à cause de la guerre, s'exiler, éprouver de la nostalgie, l'attente, "Miser tout pour tout perdre et tout gagner» sont autant de similitudes avec les traversées actuelles. "Qu'emportet-on dans l'instant? Quand il faut, du jour au lendemain, plier bagage et laisser son monde derrière soi sans espoir d'y revenir. » Nihad Jnaid 